\title{
La Unidad del Derecho Privado en Luisiana Durante el Régimen Español
}

\author{
Por el Dr. RODOLFO BATIZA
}

El "Pacto de Familia" secreto concluído entre Luis XV y Carlos III el 3 de noviembre de 1762, que dio fin a la soberanía francesa sobre Luisiana, estipulaba que la entrega sería "...en plena propieciad y simplemente y sin ninguna excepción a su Majestad Católica y a sus sucesores en perpetuiciad de todo el país conocido bajo el nombre de la Luisiana, así como la Nueva Orleans y la isla en que esta ciudad está situada." Pero no fue sino hastc el mes de agosto de 1769 cuando Dn. Alejandro O'Reilly, enviado de la corona española, tomó posesión efectiva de Luisiana, pues la misión que en tal sentido se encomendara a Dn. Antonio de Ulloa en 1766 había tracasado a consecuencia de la resuelta oposición de los habitantes, predominartemente franceses, del Territorio. ${ }^{2}$

* Profesor Asociado de Estudios Jurídicos Latinoamericanos y Director Asociado del Instituto de Derecho Comparado, Facultad de Derecho de la Universidad de Tulane.

El autor expresa su, sincero reconocimiento al Consejo de Investigaciones, a la Facultad de Derecho y al Instituto de Derecho Comparado de la Universidad de Tulame por la ayuda finarciera que le permitió la investigación en el Archivo General de Indias de Sevilla en que principalmente se basa el presente estudio.

A menos de indicación en otro sentido, los documentos citados en el texto se encuentran en el Legajo $\mathrm{N}^{\circ} .2594$ "Planificación". Sección Quinta, Luisiana Y Florida, Audiencia de Santo Domingo. Los diversos legajos relativos a Luisiana fueron primercmente enviados a Cuba, y el Archivo General de la Isla, en cumplimiento de la Real Orden de 19 de abril de 1888. los remitió a España.

1 El original froncés do esta transcripción aparece en el documento en que Carlos III aceptaba o ratificaba el acto de cesión, ya que el Marqués de Grimaldi, su Embajador Extraordinario ante el Rey de Francia, to había admitido "tan sólo sub spe rati". El párrafo completo dice así: "Pour cet effet le Roi trés Chretien a crutorisé le Duc de Cheiseuil, son Ministre, a délivrer dans la forme la plus autentique, au Marquis de Grimaldi, Ambassadeur Extraordinaire en toute prorieté et simplement et sans exceptión, a S.M.C. et a seos succesiseurs a perpétuité tout les Pays connus soup le nom de a la Louisiana, aussi que la Nouvelle Orleans, et l'Isle dans la quelle cette Ville est située". (sic). (Legajo 2542).

- Tratan en detalle la situación, principalmente: Francois-Xavier Martin: "The History of Louisiana, From the Earliest Period". New Orleans, 1882, Charles Gayarré: "History of Louisicna", Vols. II y MI, New Orleans, 1885. Martin de la versión siguiente: "El 17 y 18 de enexo de 1768 el frío más intenso de que tuviera noticia se sintió en Luisiana. El río 
A esa oposición de los colonos se ha atribuído la decisión de $0^{\prime}$ Reilly, en su proclamación de 25 de noviembre de $1769,^{3}$ de abolir el Ccnsejo Superior y derogar el sistema jurídico francés prevaleciente en la Colania. ${ }^{4}$ En el preámbulo de dicha proclama, O'Reilly explicaba su proceder en la forma siguiente:

"Por cuanto del proceso formado sobre la sublevación de esta Co-
lonia, y sus posteriores inquietudes, se ha evidenciado la parte e
influjo que el Consejo tuvo en aquellos movimientos, apoyando unos
actos de tan grave criminalidad, cuando su principal objeto debia
consistir en refrenar el Pueblo y mantenerlo en la fidelidad y subor-
dinación debida cl Soberano; por cuyo motivo, consultando el re-
medio para lo sucesivo, se hace preciso abolir dicho Consejo y en
su lugar establecer la forma de Gobierno político y administración
de justicia que prescriben nuestras sabias Leyes, y con que todos
los dominios de S.M. en América se han mantenido siempre en

se heló frenle a Nueva Orleans de una longitud de varias yardas en ambas riberas. Los naranjos quedaron destruídos en toda la provincia. - Se habian celebrado asambleas par. ciales er la ciudad y en la "Costa Alemana". En esta última había reinado perfecta unanimidad. El Fadre Beinabé, misionero capuchino que era cura de esa parroquia, tomó parte activa junto con los más influyentes de su grey. Por último, se invitó al pueblo de la pro. vincia a una asamblea general en Nueva Orleans, a la cual cada parroquia onvió a sus hacendados más acaudalados. Lafreniere tue de nuevo el orador principal. Y fue cpoyado por Jean Milhet, Joseph Milhet, su hermano, y Doucet, un abogado recién llegado de Francia. E! acto terminó con la tirna de una petición dirigida al consejo superior para ordenar a Ullor y a los principales oficiales de las tropas españolas la retirada. La petición circuló en toda la provincia y recibió quinientes cincuenta firmas respelables. Su impresión fue auioiradc por el ordonncteu: $y$ se ervió a cada parroquia...Por último, el 29 de octubre... y dépués de algun éebate. el conesjo (a pesar de la oposición y protesta de Aubry) ordenó a Ulioa exhibir las facultades que tenía del Rey de España, si es que alguna tenía, para que constaran en el acta y se publicaran en toda la provincia, o que saliera de ésta dentro de un mes de plazo... Ulloa escogió la última de las altennativas propueslas..." Op cit suprir pp. 201 y s.

3 Martin da como fecha el 21 de noviembre, op. cit. supra nota 2. p. 209; Gayarré indica el 25 de noviembre, op. cit. supra. nota 2, Vol. III, p. 2. Esta última bacha es la que aparece en el impreso, considerado rarisimo, de la proclamación.

* Gayarré se expresa así: "Se recordará que Luis XV, en su carta al Cobemador D'Abadie, después de la cesión de Luisiana a España, había expresado el deseo de que Luisiana preservara las leyes. instituciones y usos a que había estado tanto tiempo acostumbrada, y habia declarado que esperaba de la amistad de su primo el Rey de España que, para el bienestar y tranquilidad de los colonos, ese monarca daría a sus aticiales en la provincia las instrucciones que permitieran a los jueces inferiores, lo mismo que a los del Consejo Superior, administrar justicia conforme a las antiguas leyes, formas y usos do les :coionia. Tal había sido, en un principio, la intención de su Majestad Católica, pero fue .caribiada por los acontecimientos que ocurrieron en la colonia en 1768... Tal vez el Rey de España, que no podía decentemente haber desatendido los deseos expresados por el Rey de Francia con respecto a su donación real, no fus tardo en aprovecharse de la oportunidad que le ofrecía la insurrección de la colona para rehusar la continuidad de la orga. nización francesa $y$ rehacerla según el estilo español. Era natural para los estadistas do España considerar sana política asimilar la nueva adquisición a sus otras posesiones $Y$ 
la mayor tronquilidad, contento y subordinación. For tanto, usando de ia facultad que el hey nuestro Señor (que Dios guarde) se ha dignado conferirme por su Real Cédula expedida en Aranjuez a diez y seis de Abrii de este año, para establecer en lo militar y politico, administarción de justicia y manejo de su Real Hacienda la forma de gobierno, dependencia y subordinación que convenga en esta Colonia. ERIJO en su Real Nombre un Cabildo, Justicia y Regimiento en esta Ciudad, con el número de seis Regidores Perpetuos, conforme al espíritu de la Ley 2a. Tít. 10. Lib. 5. de l. Recopilación de Indias, en los cuales han de quedar refundidos los oficios de Alférez Real, Alcalde mayor Provincial, Alguacil mayor, Depositario general y Receptor de Penas de Cámara, eligiéndose por estos el día primero de cada año, dos Alcaldes ordinarios, un Síndico Procurador general y un Mayordomo de Propios, según las Leyes determinan para el buen gobierno y administración de justicia de las Ciudades. Y atendiendo a que la inopia de Letrados en este Pás, y las pocas luces que tienen estos nuevos Vasallos del derecho de España, podrían dificultar la más exacta observancia de nuestras Leycs, que es la intención de S.M., he tenido por conveniente formar un compendio o reglamento ajustado a las mismas Leyes que sirva de norma elemental para la administración de justicia y gobierno económico de esta Ciudad, mientras que introducido el Idioma Español, se facilita y adquiere más extenso conocimiento de lo concerniente a sus respectivas materias. En cuya consecuencia, a reserva de lo que S.M. tuviese por más de su Real agrado, ordeno y mando a la Justicia, Cabildo y sus Oficiales, se arreglen puntualmente a lo prevenido en los artículos siguientes."s

Se ha negado que O'Reilly tuviera facultades para actuar como lo hizo. Un conocido abogado de Nueva Orleans del siglo XIX, Gustarus Schmidt, se expresa en la siguiente forma:

\footnotetext{
borrar todo lo que pudiera tender a conservar o revivir en la colonia el recuerdo y las penas del pasado". Op. cit supra nota2, pp. 2 y s. Martin atirma: "Las premisas podrán haber sido verdaderas, pero la conclusión era ciertamente ilógica. La indiscreta conducta de unos cuantos miembros del consejo, las medidas violentas adoptadas por algunos de los habitantes, no podian en verdad atrikuirse a la organización de ese tribunal ni a las leyes, costumbres y usos que hasta entonces habian prevalecido en la provincia" $O_{p}$. cit. supra nota 2, p. 209.

Con toda imparcialidad, deberá reconocerse que los deseos expresados por Luis XV no fueron dirigidos a Carlos III directamente, aparte de que la cesión de Luisania se había hecho "en plena propiedad y simplemente y $\sin$ excepción". Vid. supra nota 1 .

"Que ascendian a 88, distribuídos en las materias siguientes: 1 . Del Cabildo; $\mathbb{I}$. De los Alcaldes Ordinarios; III. Del Alcalde Mayor Provincial; IV. Del Alguacil Mayor; V. Del Depositario General; VI Del Receptor de Penas de Cámara; VII. Del Procurador Gene. ral; VIII. Del Mayordomo de Proprios; IX. Del Escribano de Cabildo Y Gobierno; X. de las Córceles y Carceleros.

Además de la reglamentación que precede, fueron preparadas unas "Instrucciones en cuanto a la forma de promover juicios, civiles y penales, y de pronunciar sentencias en
} 
"...Cuáles eran las facultades de O'Reilly, que afirma actuaba por virtud de una patente expedida en Aranjuez el 16 de abril de 1769... es todaría un misterio que no estamos en aptitud de resolver porque Jos Estados Unidos, a pesar de los repetidos esfuerzos y solicitudes ante la Corte de España no han podido obtener una copia de su comisión que, si hemos de dar crédito a una Real Orden dirigida a Lon Pedro García Mayoral fechada en El Prado el 28 de enero de 1771, se expidió el 29 de octubre de 1768 y no en abril de 1769, como la ordenanza lo declara... Que la facultad de O'Reilly se extendiera a un cambio total de las leyes del país no puede creerse sin prueba al efecto, y es negada por las ordenanzas por él publicadas en que se refiere a la futura sanción de sus medidas por parte del Rey de España. También resulta contradicha por el Informe del Consejo de Indias sobre las medidas de O'Reilly, hecho por orden del Rey el 27 de febrero de 1772, en que se dice que O'Reilly fue designado para tomar posesión de Luisiana y "establecer aquella forma de gobierno que sea más compatible con la condición del país, su clima $\mathrm{y}$ el carácter de los habitantes"...También se dice ahí que O'Reilly "considera necesario que la provincia quede sujeta a las mismas leyes que los otros dominios de América"...y se recomienda que se expidan Cédulas a tal efecto. Estos documentos, que no fueIon obtenicios sino hasta 1833, prrecen apoyar plenamente la posición del Sr Jefferson * de que O'Reilly introdujo sólo un cambio parcial en la legislación de la colonia y dejó al Rey de España determinar, después de consulta con su Consejo de Indias, si sería aconsejable sujetar a Luisiana a las mismas leyes que todas las demás colonias españolas en América. Esta opinión parece haber sicio dada. aun cuando no tengamos prueba de que jamás se haya seguido"is

general, de conformidad con jas leyes de la Nueva Recopilación de Castilla y la Recopilación de las Loyes de Indias para el gobierno de los jueces y parles litigantes, hasta que un más extenso conocimiento general del idioma español e información sobre esas leyes puede adquirirse, resumidas y arregladas por el Doct. Don Manuel Joseph de Urrustia (sic) $y$ el consejerc Don Félix Rey, por orden de su, excelencia Don Alexander O'Reilly. Gobemador y Capitán General de esta Provincia, por comisión especial de Su Majestad. Dichas instrucciones se referían a las materias siguientes: Sección I. De los Juicios Civiles en General; Sección II. De los Procedimientos Ejecutivos: Sección III. De la Sentencia en Causas Penales: Sección IV. De las Apelaciones; Sección V. de ias Penas; Sección VI. De los Testamentos Vid. infra nota 11 .

"En el litigio conocido por "ihe batture question", Vid. el estudio indicado en la nota siguiente.

"Sid. Gustavus Sichmidt: "The Batture Question", en The Louisiana Law Journal, Vol. I. No. 2, agosto, 1941. pp. 98 y s. Vid. supra nota 4. Los autores que no niegan o ponen en duda las facultades de $O^{\prime}$ Reilly como Martin, op. cit. supra nota 2, p. 205, Y Gcyarré, op. cit. supra nota 2, Vol. III, p. 2, parecen apoyarse únicamente en la proclamación. En carta fechada el 12 de octutre de 1841, dirigida al Sr. Gustavus Schmidt, el Sr. Julien Seghers, que la firmabo, indicó: "Que las facultades de O'Reilly eran ilimitadas, y por supuesto se extendím a un cambio total de las leyes del país, parece probable en extremo; pero, aun haciendo a un lado por completo este punto, no puede negarse el hecho 
Las afirmaciones anteriores hacen del mayor interés reproducir el texto de la Real Cédula expedida en Aranjuez el 15 de abril de 1769, asi como transcribir los demás documentos relevantes para dejar definitivamente aclarado el punto. Dice así la citada Cédula, cuyo texto ha permanesido inédito durante casi dos siglos:

"Dn. Alejandro O'Reilly, Caballero Comendador de la Orden do Alcóntara, Teniente General de mis Ejércitos. Confiado en vuestra actividad $y$ notorio celo de mi Real servicio, os he destinado a la América con varias comisiones: y siendo la principal de ellas de tomar formalmente posesión de la Colonia de la Luisiana que me cedió el Rey Cristianísimo mi muy caro y muy amado primo, ho resuelto que llegéis a la Isla de Cuba, tomando en ella la tropa reglada, municiones y demás aprestos que juzgareis necesario, os transladéis a la Colonia, y después de posesionaros de ella en mi Real nombre, forméis procesos y castiguéis conforme a Leyes a los motores y cómplices de la sublevación que hubo en el Nuevo Orleans contra Dn. Antonio de Ulloa a quien envié anteriormente para Gobernador de dicha Colonia: arrojando $y$ haciendo salir de ella $\alpha$ todas las personas y familias que juzgareis no deben quedar en aquel País sin riesgo de su tranquilidad; $Y$ estableciendo así en lo militar como en lo político, administración de justicia y manejo do mi Real Hacienda, la forma de Gobierno, Dependencia y Subordinación que según lo que lleváis entendido y se os advierta después iuere conveniente. Para que pongáis en práctica todo lo expresado os concedo tan amplio y pleno poder y jưrisdicción como la calidad

de que las crdenanzas de los virreyes, gobernadores y otros funcionarios coloniales del gobierno español, a'unque siempre sujetas a la sanción futura del rey, eran, sin embargo, mientras no fueran abrogadas, obligatorias para los habitantes de la provincia. Ahora bien, las ordenanzas de O'Reilly jamás fueron abrogadas; por lo contrario, su opinión de que Luisiana fuera gobernada por las leyes españolas fue aprobada en 1772 por el Consejo do Indias, y para dar mayor fuerza a lo que ya habia hecho O'Reilly tres años antes, se recomendó que se expidieran Cédulas para ese efecto. Esta opinión no parece haberse seguido nunca, y en realidad no habia necesidad de ello. Las leyes españolas ya estaban en pleno efecto en Luisiana". Vid. "The Louisiana Law Journal", Vol. I. No. 4, pp. 25 y s.

El Sr. Seghers transcribía en su carta una cita tomada de Derbigny, que dice en parte: "es imposible saber hasta dónde estaba autorizado el olicial español que tomó posasión de Luisiana para introducir las leyes de España. Es probable que no haya depositada en los archivos de la colonia copia alguna de sus instrucciones, o que, si lo hizo, ésta hay I desaparecido antes de que el país fuera entregado al gobieno de los Estados Unidos. No nos queda sino dar por supuesto que él no actuó sin autorización. En su respuesta a la carta del Sr. Seghers, Schmidt hizo, entre otras, las siguientes afirmaciones: "... O'Reilly era el mantatario del soberano español, y como tal estaba en el predicamento de todo ctro mandatario, esto es, estaba obligado a exhibir sus poderes; $y$, hasta que no lo hicierc, no tenía dereche a actuar por su mandante... La suposición de que $O^{\prime}$ Reilly estaba facultado a fin de legisiar para Luisiana, nos parece, por tanto, desprovista del más leve grado dia probalidad, por encontrarse en directa oposición a las leyes de España y a las reglas conocidas que quiaban a los soberanos de ese país en la designación de sus gobernadores coloniales". Op. cil., pp. 30, 35 . 
de los asuntos, casos e incidencias necesiten; $y$ quiero que si fuese necesario uséis de la fuerza y armas que han de ir a vuestras órdenes: y que para los procedimientos judiciales llevéis en vuestra compañía por Ásesor y Promotor Fiscal los letrados que fueren de vuestra satisfacción, los cuales ejercerán estos oficios con sólo el nom. bramiento vuestro, que así es mi voluntad." (Ell subrayado es nuestro).

Además de las afirmaciones en el sentido de que la abolición del Ccnsejo Superior fue un acto de represalia y que la oposición de los colonos franceses un pretexto para la implantación del régimen jurídico colorial español, ${ }^{7}$ se ha hecho también la aseveración de que el monarca español había tenido en un principio la intención de mantener en la Colonia el régimen jurídico francés. ${ }^{8}$ Sin embargo, otra Real Cédula fechada en Aranjuez el 22 de marzo de 1767, demuestra la inexactitud de las dos primeras afirmaciones y la exactitud sólo parcial de la última. ${ }^{9} \mathrm{Su}$ texto $\mathrm{es}^{\circ}$ el siguiente:

"Dn. Antonio de Ulloa, Caballero de la Orden de Santiago, mi Gobernador Político y Militar de la Provincia de la Luisiana. Sabed que habiendo examinado el método con que en esa provincia se administra la Justicia Civil y Criminal y considerando que las personas de que se compone el Consejo Superior de ella, es casi imposible se dediquen al despacho de los Pleitos, Causas y negocios que ocurran con la continuación que se necesita por estorbárselo sus ocupaciones peculiares y domésticas. Deseoso yo de que esos nuevos súbditos experimenten desde luego mi real beneficencia y se cseguren de que siempre ciudaré de mantenerlos en paz, en justicia y en buen orden, y que les dispensaré todo el favor y ventajas posibles: he determinado se ejecute lo que se expresará en los nueve artículos siguientes: ${ }^{10}$

10. Que desde el día en que se tome posesión de la Provincia de Lusiana que me ha cedido el Rey Cristianísimo mi primo, se tenga por extingrtido el Consejo Superior de ella de modo que no haya de conocer de ninguna de las causas civiles ni criminales ni de ningún

7 Vid supra nota 4.

s lbid.

9 Parecería más bien que una decisión tomada con anterioridad fue impuesta por la fuerza en rizón de la conducta de los colonos. Vid supra nota 2 .

10 Las disposiciones omitidas en el texto son las siguientes: 20. Que a los Consejeros y Frocurador General que gazan sueldo, se les pague como si estuvieran en actual ejercicio. el que S.M. Cristianísima les pagaba con calidad de que vivan en la Colonia, pues si transladaren su domicilio a otra parle les deberá cesar, como lambién les cescrá si se les empleare en otro destino con sueldo señalado, pues ningún dependiente de la Colonia deberá gozar dos sueidas. 5o. Que en las causas y pleitos que ocurran de nuevo interin pasa a dicha Provincia el Asesor que yo elija, se asesore el Gobernador con uno de los consejeros del Consejo Superior extinguido. 79. Que los pleitos y causas civiles y criminales que estuvieren pendientes al tiempo de tomar posesión se terminen y concluyón en última instancia 
otro género de recursos, que desde entonces ocurran, y se empiecen de nuevo.

30. Que desde el día de la posesión de la Colonia en adelante sea tenido el Gobernador actual y sus sucesores por fuer superior de ella a cuyo cargo corra toda lo perteneciente a Justicia Civil y Criminal, Gobierno Político y Policía, con facultad de resolver y sentenciar todos los Pleitos, Causas, Recursos e instancias que desde entonces ocurran y se introduzcan de nuevo, ya sea por los naturales del país, ya por Españoles o ya por Extranjeros, a cuyo fin le concedo la Jurisdicción necesaria, dejando sujetos a él todos los empleados en dicha administración de Justicia, Gobierno Político y Policía.

40. Que para actuar, substanciar y determinar los Pleitos y Causas Civiles Y Criminales, tenga el Gobernador un Asesor Letrado con el título de Auditor de Guerra, Asesor de Gobierno, cuyo nombramiento reservo $\mathrm{n}$ mí.

$6^{\circ}$. Quib los Pleitos y Causas Civiles y Criminales que se ofrezcan a los naturales del País entre sí mismos o con algún Español o Extranjero, se actúen, substancien $y$ determinen conforme a las Leyes $y$ costumbres que tengan uso constante $y$ seguido en la Colonia, $y$ en los casos no prevenidos o dudosos, por las Leyes de la Nueva Recopilación de Indias: pero si el Pleito fuere entre Españoles, deberón ser juzgados por dichas Leyes de Indias .

8o. Que los recursos y apelaciones de las sentencias del Gobernador en los negocios que ocurriesen desde el día de la posesión en adelante y las que dieren los ministros del Consejo Superior, por lo tocante a los Pleytos y negocios antiguos hayan de venir a mi Real Persona, por medio del Ministro de Estado a cuyo cargo estuviere la Provincia de la Lusiana.

9o. Y que el Comisario Ministro General de Guerra y Hacienda ds la Colonia no tenga intervención alguna en los asuntos de Justicia y Policía no obstante lo que se previene en su Instrucción, y lo que se haya practicado hasta aquí en dicha Colonia, para que de este modo pueda dedicarse enteramente a los propios de su ministerio y a los demás que yo ponga a su cuidado. Y para que los expresados nueve artículos tengan su debido cumplimiento os mando los publiquéis $y$ pongáis en práctica luego que hayáis tomado posesión de esa Co. lonia, y que así voz como los demás ministros y oficiales míos $y$ todos los naturales de ella de cualquier calidad y condición que sean cumpláis y ejecutéis exacta e inviolablemente lo que por ellos se dispone, que así es mi voluntad". (EI subrayado es nuestro).

ante los consejeros que componian el Consejo Superior, a los cuales conservo la jurisdicción necesaria para este solo fin $Y$ para que estos pleitos instanciass se concluyan con toda la brevedad posible, dispondrá el Gobernador que tengan sesiones trecuentes y arregladas; $y$ si por largo tiempo se excusare alguno a ejecutorlo sin causa legítima so lo suspenderá el pago de sueldo $y$ se me dará cuenta". La expedición de la Cédula de 22 de marzo de 1767. demuestra que Ulloa no se limitó, en las palabras de Martin, op cit. supra nota 2, p. 208, a: "Durante casi dos años, haber rondado la Provincia como un fantasma de autoridad dudosa". 
O'Reilly había tenido la precaución de dirigir al Consejo de Indias la comunicación de fecha 17 de octubre de 1769, del tenor siguiente:

"Por todos respectos concibo necesario que esta Provincia se gobierne por las mismas leyes que los demás Dominios de S.M. en América y que todo se actúe en la lengua española; con esto seróx fócil establecer las apelaciones a los Tribunales superiores, sin cuyo consuelo sería sobrada la independencia de quien aquí mandase, 0 tendría el Rey que establecer nuevo Tribunal con Jueces inteligentes en distinlas leyes a idioma extranjero, y respecto de que este consejo quedará abolido, usando de las facultades que el Rey mo ha concedido en su real cédula fecha 16 de Abril del corriente año, yo estableceré este Gobierno bajo los principios que llevo expuestos, interim S.M. resuelva lo que fuere de su mayor grado:

La apelación de las sentencias del Gobernador y Alcaldes de esta Ciudad padecería infinito atraso y gastos a las Partes si se estableciere a la Audiencia de Sto. Domingo; esta Provincia no tiene con aqualla trato alguno ni otra ocasión que la del situado," que va una vez al año desde La Habana, y la del correo marítimo, que primero regresa a España para volver a Sto. Domingo.

Se evitarían los expresados inconvenientes con establacer las apelaciones en lo civil y criminal a La Habana, y formar allí un Tribunal con este objeto, que sin gasto del Erario podría componerse del Capitán General, como Presidente, el Auditor de Guerra, el Auditor de Marina, el Fiscal de Real Hacienda y el Escribano de Gobierno; con este establecimiento tendrían estos Habitantes inmediata y poco costosa la primera apelación, y les quedaría después el consuelo de tenerla en derechura al Consejo de Indias, como la tenían antes al Consejo privado del Rey de Francia.

Me parece que también convendría que este Gobierno tuviese la misma dependencia de la Capitanía General de La Habana y Miniztario de Real Hacienda, que ha tenido siempre la Florida y awin tiene el Gubierno de Cuba; serían entonces más prontos y mutuos los socorros; habría menos embarazos en todo; las fuerzas que hay en La Habana causarían aquí grande respeto; las de aquí se transportarían allí si necesario; y tanto en lo militar como en lo civil, criminal y Real Hacienda, habría Jefes autorizados e inmediatos para fiscalizar a éstos y que no tendrían interés alguno en sufrir sus abusos; yo concibo el establecimiento de este Gobierno del modo expresado sumamente ventajoso a todos los objetos del servicio y bien de estos Vasallos; lo hago presente a V.E. con la

* Las sumas periódicas que se enviaban a las posesiones españolas que no podian bastarse a si mismas financieramente. Esto ocurría p. oj, en Puerto Rico y Luisiana, que racibian el situado de la Nueva España. 
justa desconfianza del acierto, que tanto anhelo en todo lo relativo: al servicio de S.M.". ${ }^{11}$.

Por último, tanto las medidas que adoptó O'Reilly en Nueva Orleans, como las sugestiones que hiciera para llevarlas a mejor efecto, merecieron la aprobación real según resulta del documento de fecha 27 de enero do 1770, que a la letra dice:

"En carta de 17 de octubre del año próximo pasado No. S. dice V.E. concibe necesario que esa Provincia de la Luisiana se gobierne por Ias mismas Leyes que los demás Dominios de S.M. en la América, actuándose todo en Lengua Española; bajo cuyos principios, usando: V.E. de las facultades que el Rey le tiene concedidas, establecerá ese Gobierno interim resuelve S.M. lo que sea de su agrado: Que las apelaciones de las sentencias del Gobernador y Alcaldes de la. Provincia causarian mucho dispendio a las partes y padecerían infinito atraso si hubieran de ir a la Audiencia de Santo Domingo, cuyos inconvenientes se evitarían con establecer las apelaciones en lo civil y criminal a La Habana, formando allí un tribunal con ese objeto, que sin gasto del Real Erario podría componerse del Capitán como Presidente, del Auditor de Guerra, del de Marina, del Fiscal de Real Hacienda, y del Escribano de Gobierno; pues facilitando de este modo $\alpha$ esos Habitantes una apelación inmediata y poco cos. tosa, les quedaría después el consuelo de segunda apelación al Consejo de las Indias, como lo tenía antes al Consejo privado del Rey de Francia: $Y$ que también juzga convendría que ese Gobierno quedase dependiente de la Capitanía General y del Ministerio de

11 Con fecha lo. de diciembre de 1769 O'Reilly envió esta comunicación: "El día 26: cel mes próximo pasado hice la elección de seis Regidores para formar Cabildo y Regimiento: en esta Ciudad: el día primero del corriente los junté en mi casa, tomé a cada uno el juramento que previenen las leyes de indias, y después de exhortarlos al exacto desempeño de la confianza que S.M. depositara en ellos, di en dicho Cabildo posesión del Gobierno político de esta Ciudad al Coronel Dn. Luis de Unzaga, previniéndole que el dia siguiente presidiese: el Cabilcio $Y$ se hiciere en él elección de dos Blcaldes Ordinarios, un Síndico Procurador General y un Mayordomo de Proprios; ejecutóse asi. dando el Cabildo a conocer en sus elecciones su deseo de acierto.- Remito a manos de V.E. una relación que explica el nombre de los Regidores, Alcaldes, Síndico Procurador y Mayordomo de Proprios, con dos impresos que con exacto arreglo a las Leyes de Indias he hecho formar por mi Asesor Dn. Manuel de Urutia y mi Promotor Fiscal Dn. Félix Rey; el uno es para la erección de este Cabiláo e instrucción de los que lo componen; el otro es para el gobierno de los jueces en las causas fudiciales, lo que facilitaría su desempeño, dará a las Partes el conocimiento necesario, y hará que el Público reciba mejor la mudanza de Gobierno, a cuyc fin he hecho imprimir en francés dichos papeles. Me ha parecido muy preciso el abolir formalmente el antiguo Consejo de esta Provincia e instruir el Público y la Europa de los motivos que ha dado al Rey para tan nece. sarioy justa resolución: consideré propia esta ocasión para ejecutarlo: a este fin formé el papel que sirve de encabezamiento al primer impreso y lo hice publicar separadamente para notcriedad de todos; me será de infinita satisfacción que las razones y cláusulas con que fundo y explico determinación tan importante merezcan la aprobación de S.M. como asimisma el tiempo y modo con que he dispuesto esta mudanza de Gobierno". 
Ia Real Hacienda de La Habana, al modo que la está el Gobierno de Cuba.

Habiendo merecido estos dictómenes de V.E. Y las sólidas rarones en que los funda la aprobación del Rey, ha determinado S.M. se ejecute todo como V.E. propone. Y respecto que en la mayor parte esiará ya puesto en práctica en virtud de las facultades con que S.M. autorizó a V.E., es su Real ánimo que continúe como V.E. lo haya dispuesto, interin se expidan por el Consejo de las Indias las Cédulas y Despathos correspondientes a su formal plantificación y a la incorporación de esa Provincia en sus Reales Dominios de América: a cuyo fin, $y$ antes de expedir los citados. Despachos y Cédulas, communicará S.M. orden a dicho Consejo para que consulte las ampliaciones o reparos que se le ofrezcan". ${ }^{12}$.

12 Las Cédulas y Despachos correspondientes a la formal "plantificación" e incorporación de Luisiana en los Reales Dominios de América no figuran en los legajos respec. t:vos cel Frchivo General de Indias. particularmente el No. 2594 "Plantificación". Sin embargo, tales documentos - si existieran - no pasarían de ser la última formalidad. Por cuanto. a la ratificación de los diversos actos realizados por O'Reilly, la actitud de Carlos III es vuficientemente clara. El único documento que encontramos tendiente a la expedición de las cédulas y despachos citados es el que a continuación se transcribe, fechado en Madrid el 10, de julio de 1771: "La Contaduría ha expuesto cuanto cerca de ellas se la ha ofrecido. y reserva su cprcbación a la notoria justificación del Consejo para que estimando justas y arregladas todas las providencias tomadas por dicho Oficial General en los diferentes puntes que abrazan sus escritos, se sirva expedir las Reales Cédulas que convengan a efecto de que e) Cobierno Político y Militar y de Real Hacienda. siga bajo el pie en que lo dejó estableridc. interin que por la variación del tiempo, circunstancias que puedan ocurrir, o inconvenientes que se foquen en lo sucesivu, sea conveniente alterar alguna de la presentes disposiciones". De todas marieras, la posible falta de las cédulas y despachos no impidió el que España siguiera ejerciendo su soberanía al designar como gobemadores sucesivos de Luisiona a Unzaga, Gálvez, Miró, Corondelet. Gayoso, Casa Calvo y Scilcedo, hasta que por el Tratcado ce San lldefonso de 1o. de octubre de 1800 hizo cesión de Luisiana a Francia. Este punto. de vista ccincide en lo esencial con el expuesto por Seghers. Vid. supra nota 6. Es evidente que el legrajo No. 2594 no contiene todos los documentos pertinentes a la "plantificacion" ce Luisiana. En relación con esta afirmación y con la ratificación de los actos de O'Reiliy. es de gran irterés el siguiente comentario de Gayarré: "El Juez Martin, en su Historio. de Luisiena, alirma: "Carios III desaprobó la conducia de O'Reilly, que recibió, al desembarcrr en Cádiz, una orden que le prohibía comparecer ante la Corte". Estc aseveración parece cescansar en la muy talible autoridad de la tradición. y es ciertamente incompatible con los documentos oficiales en Existencia. Así, el 28 de enero de 1771 el Rey de España envió a su Consejo de Indias ura comunicación en que le informaba que sometía a su conside. ración lodos los actos de la administración de $O^{\prime}$ heilly en Luisiana, que él aprobaba pleraneate, pero respecto a los cuales no cbstanie deseaba tener la cpinión de su liel Consejo. La respuesta fue en el sertido de: "que el Consejo, habiendo examinado cuidadosamente todos los documentos a los que el Rey había llamado su atención, no podía descubrir en les actos de O'Reilly nada que no mereciera la más decidida aprobación y que no fuera prueba sciable del genio extraordinorio de ese oficial general". ¿Se le hubiera hejho semejante elogio si bubiera sido sospechoso de haber excitado el más leve disgusto reai? No sólo lcécs sus actosi sino también todas sus sugestiones, fueron sancionadas, con una excepción cislada que parece dar aún más fuerza al elogio general expresado, como a tado lo demás, por el Rey y su Consejo. Esta excepsión se refiese al artículo 6o. de la sección 
En la form: que tan explícitamente reflejan los diversos documentos transcritos en las páginas que preceden, Luisiana quedó, en lo general, ${ }^{13}$ incorporada al sistema jurídico y político vigente en los demás dominios españoles del Hemisferio. La legislación de Indias, dictada desde la me. tropolii' para regir en los dilatados territorios de América, en el curso

5 sub:e penas, en que O'Reilly expresó: "La mujer casada que adultere y el adúltero sean entregados al marido para que haga con ellos lo que quiera, con tal que no pueda matar a! uno sin matar al oiro" El Consejo derlaró que este articulo "cuya lectura les habira causado bastante repugnancia, se considerase como suspenso y no escrito". Este crtículo, sin embargo, no kabia sido elabsrado por O'Reilly sino que habia sido tomado dal iibro 8 do la "Nueva Recopilquión de Castilla". Además, es bien sabido que O'Reilly se mantuvo on el elevalo favor de la Corte hasta la muerte de Carlos III". Op. cil. supra nota 2, pp. 37 y ss

1: Quizá la excepción de mayor importancia se ensuentre en materia de tráfico co. me:cial Haring destribe asi la situación: "La concesión más notable al nuevo espíritu quo animaba la pelítica del gobierno the hecha en 1782. Luisiana, adquirida da Francia doa décadas antes, con una pob:ación pieponderante francesa acostumbrada a los artículos franceses, amenazada al mi:mo tiempo por las intrusiones anglamericanas provenientes del norte, no podía ser abastecida en forma adecuada por el comercio de España. Si la prospeikiad de la provincia iba a ser mantenida. para no decia nada de su lealtad a la coro. na españcla, el intercambio comercial con alguna nación extranjera parecía esencial. Y por muchas razones: el tráifico con Francia era la elección naturas. De hecho, durante la guirra con Inglateria, las autoridades coioniales en Luisiana, habian sido forzadas a aceptarlo. Un decreto recl del 22 de enero de 1782 , por tanto, permitió que los terrcos propiedad de súbcitos españoles en España o Luisiang transportaran cargamentos a Nueva Orleans o Peisacola directamenie de cualquier pue:to francés en que hubiera un cónsul españcl y regresar con productos de América, excepto oro y plata". Vid. "The Spanish Empira in Annexica", Oxtord University Press, New York. 1947, p. 342. Como lo observa un autor, "el pueblo de Llisiana the gobernado pcr el Fuero Viejo. Fuero Juzgo, Partidas, Recopilaciones, Leyes de Indias. Autos Acordados y Cédulas Reaies. Vid. Loevy: "Louisiana and Her Laws", en The Louisiana Bock, T, 1, p. 6, 1894.

14 Como dice Pereyra con acierto. "La legislación de Indias debe tener por pijmer capitulo una disposición de última voluntad que dejó Isabel La Católica: "Cuando nos fueron concedidas por la Santa Sede Apostólica las Islas y Tierra Firme del Mar Océano, descubiertas y ps. sescubrir, nuestra principal intención fue al tiempo que lo suplicamos al Papa Aiejando VI, de buenc memoria. fle ros hizo la cicha concesión de propurar inauel: $y$ trcer los pueblos de ellas, y los convertir a nuestra $F e$ Católice, $y$ enviar a las dichas Islas y Tierra Firme, prelados y religiosos. clérigos $Y$ otras personas devolas $y$ temercsas de Dios, para instruir los vecincs y moraderes de elias a la Fe Católica, y los doctrinar y enseñar, y enseñar buesas costumbres, según más largamente en las letras de la dicha concesión se mantiene. Suplico al Rey, mi Señor, muy afectuosramente, y encargo y mando a la princese (Doña Juana) mi hija, y al príncipe (Don Felipe el Hermoso) su marido, quo así lo hagan y cumplan, y que este sea su principal fin. y que en ello pongan mucha diligencia, y no consiemtan ni den lugar a que los indios vecinos y moradores de las dichrst Islas $y$ Tierra Firme, ganadas $y$ por ganar, reciban agravio alguno en sus personas $y$ bienes: mas manden que sean bien justamente tratados, y si algún agravio han recibido, lo remedien, y provean de manera que no se exceda cosa alguna lo que por las letras cpostólicas do la dicha concesión nos es inyungido y mandado. $Y$ nos - dicen los reyes sucescres --., mandamos a los virreyes, presidentes (audienciasł, gobernadore; y justiciaz reales, y encargamos a los arzobispos, obispos y prelados eclesiásticos, que tengan esta cláusula muy presente, y guarden lo dispuesto por las leyes. que en orden a la conversión de los naturales, $y$ a su cristiana y católica doctrina, enseñanza y buen tratamiento estón 
de los años llegó a constituir un complejo y confuso ordenamiento integrado por miles de disposiciones que se referían a las materias más variadas. ${ }^{1 . ;}$ Pero ni siquiera el excesivo casuismo ${ }^{16}$ que caracterizaba al derecho indiario (o quizá por esto mismo) podía bastar para cubrir todas las situaciones. De ahí que la Recopilación de Leyes de las Indias dispusiera:

"Ordenamos y mandamos, que en todos los casos, negorios y pleitos que no estuviere decidido, ni declarado lo que se debe proveer por las leyes de esta Recopilación, o por cédulas, provisiones u ordonanzas dadas y no revocadas para las Indias, y las que por nuestra orden se despacharen, se guarden las leyes de Nuestro Reino de Castilla conforme a las de Toro". ${ }^{17}$

Las Leyes de Toro, publicados en 1505, establecían el orden de prelación que debían seguir los jueces al fallar controversias judiciales, en la forma siguiente: en primer término, los ordenamientos y pragmáticas en vigor; en lo que fueren deficientes, debía recurrirse a los fueros municipales si no contrariaban a unos y otras; en caso de que los ordenamientos, pragmáticas y fueros resultaran insuficientes, debía recurirse a las leyes de las Siete Partidas del Rey Alfonso. ${ }^{18}$ Como es sabido, fue este Código de las Siete Partidas el que vino a ocupar en la práctica, pese a su carácter supletorio, el lugar preponderante en América. ${ }^{19}$

Tanto las Siete Partidas ${ }^{20}$ como la Recopilación de Leyes de las

dadas". Vid. Carlos Pereyra: "Breve Historia de América", M. Aguilar, Editor, Madrid. 1930, pp. 256 y s.

15 A este respecto afirma Pereyra: "Durante todo el siglo XVI so fue formando la copiosa legislación de Indias que llegó a tener más de seis mil dísposiciones sobre economía. justicia, administración, culto, higiene, instrucción, artes, letras y cuanto podía referirse $x 1$ réginen del Nuevo Mundo. En 1596 se hizo la primera recopilación de de estas leyes, que en el siglo XVII formó ya un cuerpo de nueve libros... La legislación de Indias no tue exactamente aplicada, es verdad. Pero la historia debe registrar la lucha permanente que so trabó entre la corona, defensora de la causa del indígena, y el interés de los explotadorez. Op. elt. supra nota 13, p. 255.

16 Señala Ots Capdequí que 'Este nuevo derecho, o sea el derecho propiamente Indiano, presentó pronto como rasgos más característicos, los siguientes: 1. Un casuismo acentuado y en consecuencia una gran profusión.... 2 Una tencencia asimiladora y y uniformista... 3 Una gram minuciosidad reglamentista... 4 Un hondo sentido religioso y espiritual". Vid. José Maria Ots Capdequí: "El Estado Español en las Indias". El Colegio do México, 1941. Rp. 12 y s.

$1 T$ Precepto que en lo esencial reproduce lo establecido en el Título XXVIII del Orde. namiento de Alcalá, publicado en 1348.

18 Ley Primera.

19 'Parece oportuno advertir - explica Ots Capdequí - que las Partidas. enume. radas en último lugar entre las fuentes del derecho castellano vigentes en las Indias coma derecho supletorio, alcanzaron de hecho un papel preponderante en la vida jurídica de estos territorios camo código regulador de las instituciones de derecho privado". Op. cit. supsa nota 16, p. 11, n. 1 .

20 EI Título VII de la Quinta Partida se refería a mercaderes, feriaz y mercados. La Ley 1 de dicho Título. definía a aquellos como: "Propiamonte son llamados mercadores. 
Indias, ${ }^{11}$ contenían disposiciones sobre materias mercantiles. Sin embargo, es en las diversas Ordenanzas, las de Burgos, Sevilla, y Bilbao, donde se encuentra la expresión sistematizada del derecho mercantil español de la época. ${ }^{22}$ Ya para el siglo XVIII esta rama había alcanzado un grado considerable de especialización técnica. Hay quienes niegan que con anterioriciad al movimiento de codificación del siglo XIX el derecho mercantil haya conssituído uno rama jurídica perfectamente individualizada; ${ }^{23}$ pero es indu-

todos aquellos que venden e compran las cosas de otri, con atención de las vender a otri, por ganar en eilas. E lo que han de tazer. e de guardar, es esto: que vaen de su menester lealmente, non mezclando. ni boluiendo en aquellas cosis que han de vender, otras, porque se talsassen, nin se empeorassen. Otrosi deven guardar, que no vendan a sabiendas $\mathbf{m a}$ $\cos \alpha$ por otra. E que rsen de peso, e de medida desecha, sequn tuere costumbre en aqiella tierro, o en aquel Reyno, do moraren. E quando levaren sus mercaderias de va lugat a otro, deven yr por los caminos vsados, e dar sus derechos a los que lo ovieren de dar. E sil contra esto fiziessen, ccerian en las penas que dizen en las leyes desto "Ttitulo".

21 Además de las relativas a comercio y navegación, deben recordarse las que ze réterian a los Consulados de México y Lima.

22 Afirma Tena: Importantes ordenanzas expidieron los consuladon de comercio a principios de la edad moderna. El de Burgos, antigua institución que se remonta hasta el siglo XV, decretó las ordenanzas de ese nombre, confirmadas por don Carlos y doña Juana en 18 de septiembre de 1538.. Vienen luego las formadas por el Consulado de Sevilla extablecido en 1539, y las cucies aprobó Carlos I en 1554 .. Pero las que descuellan sobre todas por su mayor importancia son las Oxdenanzas de la Universidad $y$ Casa de Contratación de Bilbac. Dis'ínguese tres etapas en la evolución de tales ordenanzas, asienta Alvarez del Manzanc: la primitiva. la antigua y la nueva. Las crdenanzas primitivas fueron redactadas en 1459 por el liel de los mercaderes, con intervención $y$ consentimiento del corregidor. Las ontiguas. formados ya por el consulado (jurisdicción obtenida por los bilbaínos en 1511), fueron conlirmadas por Felipe II $\in$ n 15 de diciembre de 1560 y adicionadas a fines del siglo XVII... Las nuevas formadas por una junta nombrada por el prior y cónsules y revisadas por una comistión que se designó al efecto recibieron la confirmación de Felipe $V$ en 2 de diciembre de 1737". Vid. Felipe de J. Tena: "Derecho Mercantil Mexicano", 1938, Librería de Porrúa Hnos. Y Cío., T. 1., pp. 49 y s.

23 Según Bunge, "A pesar de la existencia, en Europa de tantas y tan antiguas ordenanzas de derecho mercantil marítimo, así como de la de tribunales especiales, no puedo decirse que el derecho mercentil constituyera, en las edades media y moderna, una rama ferfectamente individualizaóa del derecho, pues se le consideraba más bien como una parte o torma del deredho civil. Su individualización ya neta $y$ definitiva se produjo en los primeros lustros del siglo "XIX. con motivo de la codificación del derecho moderno". Vid, C.C. Eunge: "El Derecho" (Ensayo de una Teoría Integral), Cuarta ed., Librería Juridica Y Casa Editora Valerio Abeledo, Buenos Aires, 1916 T. II, p. 270. Pero esta opinión no fuede considerarse generaimente compartida. Tena, por ejemplo, afirma: "Conviene que nos detengamos un momento a fin de puntualizar mejor la génesis $Y$ desarrollo de ese derecho estatutario (el italiono), ya que él constituye el primeir aparecimiento, acusado por la historia, de un derecho mercantil autónomo, manantial común y primitivo de que trae su origen la mayor parte del derecho moderno". Op. cit. supra nota 21, p. 33. Antes había dicho: Surgió, pues, entonces (en plena Edad Media), por espontánea virtud. un nuevo derecho, constituído primero per la costumbre, critsalizado después en ciertas leyes escritas, que recibieron el nombre de estatutos, $y$ cuyo conjunto forma el llamado derecho estatutarto. Op. sit., pp. 30,32 .

Schlesinger dice lo siguiente: "La mayor parte de estos códigos (los de comercio, europess o latinoamericanos) son partes de sistemas jurídicos en los que se ha reconocido 
dable que la existencia de una jurisdicción especial (los Tribunales del Consulado)," de una parte, y la de ordenamientos legales suficientemente com. prensivos (las citadas Ordenanzas), por la otra, suministran las requisitos fundamentales para dar individualidad propia a un sector determinado del derecho. A lo sumo, a este respecto, la promulgación del primer Código de Comercio en España sólo vino a dar carácter nacional a una rama jurídica de crden local, pero no agregó nada realmente esencial a su naturaleza de

una distinción fundamental entre actos mercantiles y civiles (no mercantiles), desde mucho antes de la época de las grandes codificaciones. Esta dicotomia fue perpetuada en casi cada país de deracho civil por la promulgación de un código de comercio separado, además del código civil básico, y que en ocasiones precedió a éste cronológicamente". Vid. Schlesinger. Rudolf: "El Código Uniforme de Comercio a la Luz del Derecho Comparaso". Revista Jurídica Interamericana. Vol. I No. 1, p. 86. Al contrastarlo con el derecho civil, Benito se expresa en estos términos: "Los caracteres intrínsecos del derecho mercantil imponen determinadas condiciones en su desenvolvimiento. Estas condiciones son: llbertad en los medios, zapidex en las transacciones, rigor en el cumplimiento de lo convenido y rapidex en la acción de la justicia. Vid: "Manual de Derecho Mercantil", T. I, p. 24, Madrid, 1924, 3a ed.

If Citando a Vivante, Tena se expresa en estos términos: "A la cabeza de la corporación hallábange colocadcs uno o varios cónsules, cuyas funciones duraban un año o seis meses; después un consejo de los más catiguos comerciuntes, elegidos por la asamblea general de los asociados. Cada cónsul, al entrar a desempeñar su cargo, juraba administrar bien la corporación y publicaba su juramento. Escrito originariamente en latín y en primera persona, contenía de ordinario reglas administrativas, procesales, industriales, sobre la higieme de los taileres, sobre los métodos de trabajo. Redactóse después en lengua vulgar. impersonalmente, aumenlando entonces las reglas de derecho privado. Tales juramentos, al mismo tiempo que las decisiones de los consejos $y$ de las asambleas, se transcribian en volúmenes llomados estatutos, siguiéndose $\sin$ más criterio, el crden cronológico... Guiada por dichos estatutos y por los usos, la justicia se administró en primera instancí por cónsules, en ia residencia del consulado, las más de las veces con asistencia de un jurisconoilto - de dos comerciontes. Procedíase sumaricmente (sine strepitu et figura iudicii), con términos brevísimos de dos o tres días siguiendo en todo la equidad (ex bono el aequo, sola reritate roi inspecta). En persona debian comparacer los litigantes, pues estaba prohibida la asistencia de ajogados y patrones. Cuando estimaba el tribunal que la causa habia quedado suíicientemente instruida, se apresuraba a cortar toda discusión mediante su sentencia. En principio, la apelación era improcedente; en aquelios negocios graves en que se permitía tal recurso, de él conocían otros comerciantes matriculados, que designaba la suerte y $a$ quienes se daba el nombre de sopraconsoli. Cuando ambos fallos eran inconformes entrs si, pedía recurrirse a una tercera decisión, que a veces se pronunciaba por el consej, general de mercaderes, el que tenía que optar por alguno de los dos fallos precedentes. De este modo nacía entonces el derecho: los cónsules y los supracónsules, que debian extraerlo de la experiencia cotidiana de los negocios, eran comerciantes; los estatutores a quienes se confiaba la redacción y revisión do los estatutos, eran comerciontes; y la asamblea general que debía aprobarlos, también de comerciantes estaba compuesta... Esa legislación estatutaria es la que gobernó la actividad mercantil de Italia desde el sighto XII hasta printipiar el XtX, y de esta corriente se ha derivado de un modo directo el contenido de los códigos, en su esencia uniformes, que rigen en el mundo". Op. cit. supra nota 21. pp. 33 y ss. Tanto el procedimiento seguido ante los consulados españoles, ccma la estructura de éstos, eran esencialmente iguales a los de las ciudades italianas. Vid. Ordenanzas de Bilbao, Cap. I, No. IV. Los funcionarios principales del consulado eran el prior, rónsules, consiliarios y síndicos, vid. Cap. II; en México y Lima prior, cónsules y diputados. Vid. Tít. 46, Lib. IX, 8. 40. de la Recopilación, ed. de 1681. 
disciplina con perfiles caracierísticos, separada del derecho común. ${ }^{25}$

Desde fines del siglo XVI se inicia en las posesiones españolas de América el establecimiento de Consulados: México (1592), Lima (1618), Caracas (junio, 1793), Guatemala (diciembre, 1793) Buenos Aires (1794), Santiagc. de Chile (1795), entre otros. Las Ordenanzas de Bilbao, en forma más que discutible, llegrron a adquirir vigencia de hecho en la América española. ${ }^{2 H}$

A dif́erencia de lo que ocurría en el resto del Imperio Español en el Hemisferio, no llegó a establecerse en Luisiana un Consulado. No se dieron aqui los presupuestos que justificaran su establecimiento. ${ }^{27}$ Podría, no obs-

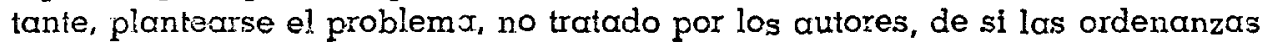

25. Señalo. Tena que "Aunque las Ordenanzas de Bilbao constituian sin duda un vercaćero códigc, como afirma Alvarez del Manzano, y obtuvieron esa especie de prioridad $Y$ de universalidad de que habla Pardessus, su carácter local impide que esa colección pueda liamarse propiamente un código español de comercio, el que no apareció sino hasta el cño de 1829". Op. cit. supra nota 21, p. 51 .

$2 "$ La préerencia de derecho correspondía a las de Burgos y Sevilla. Recopilación de Indias, ley 75, tít. 46, lib. 9. La situación en México se explica por Tena en los siguien. tes términos: "Esa general observancia (de las Ordenanzas de Bilbao) era ilegal, como acabamos de insinuarlo. Reconócelo así el mismo consulado de Iréxico, cuando insíado por el virrey para que informase acerca del uso que había hecho de las repetidas ordenanzas le contestó el 3 de noviembre de 1785 con las siguientes razones: "Que observaba, a faltux de crdenanza particular suya, lo establecido por las de Biboo, $y$ en todo lo que exan adaptables a las circunstancias del país y estilo de su comercio. Lo cual - añade - era muy conforme a lo que asienton los autores que exponen la ley primera de Toro; pies si dicen uniformemente que, a falta de ley, estatuto o costumbre debe determinarsia por la opinión de los intérpretes; con mucha más razón deberá resolverse por lo que el Soberano tiene aprobado en casos semejantes, y respecto de una misma línea, cual es la de comercio". Op. cit. supra nota 21 , pp. 50 y s. Sea que iguales o parecidas razones se hayan invocirdo en las demás posesiones españoles de América, lo cierto es que las Ordenanzas de Bilbao rigieron cie hecho en todas ellas.

27 La falta de un núcleo importante de comerciantes españoles que, a su vez, hizo innecesaria una petición para erigir consulado. En cuanto al primer presupuesto, es de interés tronscribir parte de un informe sin fecha y sin firma que obra en el Legajo No. 2666. Sec. Quinta. Audiencia de Santo Domingo, Luisiana y Florida, que dice: "No obstante el comercio de la Luisiana ha sido $y$ continúa siendo de extranjeros sin que tengan parte alguna los españcles; $n i$ los coloncs más que el tanto $p \%$ de comisión, y lo que les vale el prestar su nombre para las expediciones. Ninguna han hecho los españoles desde que se publicó la cédula (de 22 de enero de 1782, por la que se permitió el comercio directo con los puertos de Francia en que hubiese cónsul español) ni los habitantes porque no tienen fondos para ellas: de modo que todo el comercio es de los franceses e ingleses con el nombre cie los colonos". En cuanto al segundo presupuesto, el de la petición especial, el texto de la Real Cédula de Erección del Consulado de Buenos Aires, expedida en Aranjuez el 30 de enero de 1794, puede considerarse típica. Dice así: "Examinado pues con la debicia atencićn este importante asunto, $y$ vista en $\mathrm{mi}$ Consejo de Estado, entre otras instancias, la que me ha dirigido el cuerpo de comercio de la Ciudad de la Santísima Trinidad Puerto de Santa María de Buenos-Âyres..." Un caso especial parece ser el relativo a Campeche, en que el Diputado a Cortes por la Provincia de Yucatớn Dn. Miguel Latiri, solicitó se estableciera Consulado en el Puerto de Campeche (Informe fechado en Cádiz el 24 de diciembre de 1811, Legajo No. 2500. Audiencia de México). La petición, empero, no prosperó. Hacia fines del siglo XVIII, como observa Haring, se establecieron diversos consulados 
de Bilbao serian susceptibles de aplicación pese a la inexistencia del tribunal especial. Aun cuando ninguno de los historiadores del derecho de Luisianx menciona a las Ordenanzas de Bilbao como habiendo estado en vigor en la Colonia, ${ }^{2 *}$ el hecho de haberse promovido diversos juicios sobre cuestiones de derecho marítimo y títulos de crédito, ${ }^{29}$ pudiera apoyar la inferencia en cuanto a la necesidad de recurrir a dichas Ordenanzas, teniendo en consideración la obligación legal de juzgar con arreglo a las leyes. ${ }^{31}$ No porque la administración de justicia durante el régimen español haya necesariamente sido "peor que en Turquía"."31 sino por la circunstan-

en la América española. Op. cit. supra nota 13. Además de los mencionados en el texto, cejen citarse los de La Habana. Cartagena, Guadalajara y Veracruz.

28 Vid., en general: Moreati-Lislet y Caileton, Prefacio a "The Laws of Ias Siete Par. tidas Which are Still in Force in the State of Louisiana", 1820; Tucker: "Source Book; of Louisiana Law", 1958 .

24: Viù. p. ej.. The Louisiana Fistorical Quarlerly, Vol. 31. ene-oct. 1948, pp. 159 Y SS.

3" La "Fórmula del Juramento que debian hacer los Gobernadores. Alcaldes y demás jueces, al tiempo de recibirse al uso $y$ ejercicio de sus Empieos"., que figuraba al final de la prociamación de O'Reilly, vid. supra nota 5, decía asi: "Dn. N. electo Gobernador, o Alcalde, etc., (según fuere el empleo o ministerio) Juro por Dios nuestro Señor. la Santa Cruz Y Evangelios: defender el Misterio de la Inmaculada Concepción de Nuestra Señora la Virgen María y la Jurisdicción Real que por mi empleo se me encomienaia, sin permitir que se usurpe en manera alguna; como también obedecer los mandatos y Reales Cédulas de S.M. y ejercer bien y fielmente dicho encargo, juxgando con arreglo a las Loyes los Pleitos que en mi Tribunal se establecieren, para lo cual consultaré con Letrados (siempre que los haya en esta Ciudad) y finalmente que no llevaré más derechos que los que por Arancel me corresponden. $\mathrm{Y}$ ningunos a los pobres". (El subrayado es nuestro). Sin embargo, las "Instrucciones" de O'Reilly no imponían la obligación de tundar jurídicamente las sentercias. Aun cuando la cbligación de "fundar" las sentencias tenga antecedentes en el siglo XVIIL, no era absoluta, ni siquiera en España. Vid. José María Manresa y Navarro: "Comentarios a la Ley de Enjuiciamiento Civil", T. II, ppp. 209 y \$., 7a. ed.. Madrid, 1953. En realidad, la falta de fundamento jurídico en las sentencias impide una afirmación categórica en el sentido de que las Ordenanzas de Bilbao no hayan sido consultadas. Iars Ordenanzas de Bilbao, empero, no fueron por completo desconocidas en Luisiana como lo priebo el sistema jurídico que se propuso en 1806 para regir en el Territorio, y que rechazó el Gobernador Claiborne, cuya Sección 2, establecía: "Y sea declarado además que en materias de Comercio la ordenanza de Bilbao es la que tiene plena autoridad en este Territorio para decidir todas las controversias a ellas relativas: y que cuando no sea suficien. temente expícita se recurra al derecho romano. a la lex mercatoria de Beawes, a Fark en seguros, al tratado de seguros de Emorigon, y finalmente a los comentarios de Valin y a los respetables autores consultados en los Estados Unidos". (sic) vid. Franklin: "The Place of Thomas Jefferson in the Expulsion of Spamish Medieval Law from Louisiana". Tulane Law Review, Vol. XVI, No, 2, Feb. 1942, p. 326. Sin emborgo, vid, nota 12, p. 324, de este articulo, en que "un Comerciante", en carta abierta publicada en la Louisiana Gaxette correspondiente al 10 de junio de 1806, entre otras cosas preguntaba a los "augustos legisiadores" (lsaac Hebert, M. Prudhome y J. Etienne Boré) si la ordenanza de "Bilbao" liguraba en sus respeqitivas bibliotecas.

31 Según frase del Prefecto Colonia Laussat, quien fue comisionado para recibir Lui-siana de Esporíra en 1803. Vid. Gayarré op. cit, supra nola 2, p. 583. 
cia de poder invocar otras disposiciones, ${ }^{22}$ la aplicación de las Ordenanzas de Bilbao no parece haber sido absolulamente indispensable.

La escisión del derecho privado entre derecho civil y mercantil, que principia en Europa desde la Edad Media y en la Améric $x$ Hispánica en los siglos XVI y XVII, y que persiste en la catualidad salvo algunas excepciones:" no llegó a producirse en Luisiana en la época española. Por víx de comentario tinal, debe observarse que después de haber ccsado ézta de ser posesión de España en 1803, el hecho de que la promulgación del Proyecto de Código de Comercio ${ }^{34}$ que debía regir en forma paralela al Código Civil no haya materializado, determinó que se retuviera en Luisiana, definitivamente, la unidad del derecho privado.

$\therefore$ Diversas cliestiones de derecho ma:sino se ragulaban, por ejemplo, en el Título IX de la Quinta fartida. Én el caso de los títulos de crédito concretamente pagriés, no se tratcibon éstos como dxurnelto; je naturitez-r expecirl pertenecientes a un orden iaridico separado del civil jine más bien cim pruebe dorubisilal cie un adeudo de caráter general, según pueda verse de los expedientes mismos y de las normas relativas en las "Instrucciones" de O'Reilly.

33 Afirma Schlesinger: "La repudiación en Suiza de la idea de un Código de Comercio aparte inicis una tendencia perceptible. Italia abolió su Código de Comercio separado e inccrporó en el nuevo Código Civil de 1940-42 materias tan tradicionalmente mercamtiles como banca, seguros, sociedades de personas y anónimas. En Holanda, donde está en marcha una revisión de los códigos existentes, se decidió igualmente prescindir del código do comercio separado. En Franca podemos observar una animada polémica entre quienes abogan por la unidad del derecho privado y los que se adhieren a la autonomía tradicional del dereche mercantil simbolizada por un código de comercio separado. En general, la tendencia de $l_{a}$ opinjón acciémica en Francia, lo mismo que en otros páses de derecho civil parece alejarse del sistema dual". Op. cit. supra nota 23, p. 96. Sin embargo, ese no es el caso en la Arérica Latina. El movimiento relativamente reciento en la Argentina que favoreco la unificactón del derecho privada, no se comparte en general en los demás países.

34 En 1823 se dio a conocer el Proyecto de Código de Comercio preparado por Edward Livingston. Pierre Derbigny $Y$ I. Mareau Lislet a solicitud de la Legislatura de Lourigiana, pero el Prcyecto jamás tue sancionado como ley. Vid. Henry Plauché Dart: "La Iniluencia de las Antiguas Leyes de España en el Sistema Juridico de Irisiana", Revista Jurídica Interamericana, Vol I No. 2, Juliodiciembre, 1959, p. 324. La adopción, en Luisiana, de "Leyes Uniformes" tales como la de Sociedades Anónimas, Conocimientos de Embarque. Títulos de Crédito, etc., ha hecho innecesaria la expedición de un Código de Comercio. La unidad def derecha privado en luisiana difiere, pues de la forma en que so logró en Inglaterra. mediante el proceso de "absorción" de la lex mercatoria por el common law durante los siglos XVII y XVIII! tampaco fue, como en el caso de Suiza - Italia, resultado de un acto deliberado de fusión, sino que el vacío creado por la falta de un Código de Comercio fue llenado mediante sucesiyas promulgaciones de leyes especiales de contenido que, en otras eircunstancias, hubiera sido "mercantil", en la concepción europea y latinoamericama do. minante.

NOTA.-Agradecemos al Sr. Prolesor Doctor Rodolto Batiza, Director de la Revista Juridica Interamericana de la Universidad de Tulane (U.S.A.), quien nos ha autorizado a publicar este interesante irabajo, del Vol. IV de su prestigiosa Revista. 